\title{
Research on Industry Characteristics and Proportions of Cash Holdings in Listed Companies
}

\author{
Wei Weng, Xiaohan Jiang, Qiufang Ren* and Lingyan Niu* \\ Yunnan Normal University, Kunming, Yunnan, China \\ vemal@163.com \\ *Corresponding author
}

Keywords: cash holdings; industry-related difference; balance theory

\begin{abstract}
Taking the A-shares companies listed on Chinese exchanges during 2012-2016 as the study samples, from the inter-industry perspective, this paper provides a study on the difference in the proportion of cash holdings between the listed companies within the same industry, and an analysis on the industry characteristics affecting the difference. The empirical results show that there is generally a significant difference in the proportion of cash holdings between the listed companies of the industry; and that the uncertainty regarding profits of the industry, uniqueness of specific products, the degree of product market competition, and the asset structure of industry are all the important industry characteristics resulting in the difference in the proportion of cash holdings. The aforementioned results prove an effective empirical support for the balance theory, and manifest that companies listed on Chinese exchanges will determine an optimal proportion of cash holdings with consideration of the advantages and disadvantages of cash holdings.
\end{abstract}

\section{Introduction}

Based on a study on financial characteristics of companies, Opler et al (1999) discovered that the stronger momentum for development that a company has, the bigger proportion of cash holdings that the company holds due to the demands for transactions and precautions - this is a milestone finding. Yang Xingquan and Wu Haomin (2009) manifested in a research that for maintaining their advantages in an intense competition, companies will keep their proportion of cash holdings at a higher level, which stated that holding more cash is an important way to cope with product market competition and reduce risks. However, some other scholars believe that a fierce competition will reduce the proportion of cash holdings and according to the agency theory, product market competition has an effect of governance. Product market competition may stimulate managers, for seeking higher business performance, to take control over the cash held for short-term profits, which will reduce the cost for agencies. Lian Yujun, for example, put forward in his study in 2011 that the more intense the competition, the lower the proportion of cash holdings.

Based on the aforementioned literatures and background, this article took the newest data, and the companies listed on Shanghai and Shenzhen A-share exchanges during 2014-2016 as the samples to, from a perspective of industry, study the cash holdings of the listed companies, and to look into whether there is a difference in the proportion of cash holdings between listed companies 
from different industries. This article also sought to provide an empirical support for the balance theory, by the analysis on the four industry characteristics which affect the difference in the proportion of cash holdings between industries, namely the uncertainty regarding profits of the industry, uniqueness of specific products, the degree of product market competition, and the asset structure of industry.

\section{Theoretical Analysis and Hypothesis for the Study}

\subsection{Hypothesis on the difference in cash holdings between industries}

As an external factor affecting a company's proportion of cash holding, industry characteristics play an important in corporate managers' decision making, including financial decisions. Thus in general, industry characteristics are closely related to a company's financial decisions. Subject to the influence by the industry characteristics, the proportion of cash holdings varies in different industries. What is more, the inter-industry difference in the proportion of cash holdings is not an individual but general phenomenon. Therefore, the first hypothesis for the study is hereby presented:

H1: In different industries, companies listed on Chinese exchange markets have a significant difference in the proportion of cash holding.

\subsection{Hypothesis Regarding the Factors Affecting the Inter-Industry Difference in the Proportion of Cash Holding}

So far there have been few studies on the factors affecting the inter-industry difference in the proportion of Cash Holding. Based on available literatures, we conducted an analysis on the four aspects, namely the uncertainty regarding profits of the industry, uniqueness of specific products, the degree of product market competition, and the asset structure of industry.

\subsubsection{The uncertainty regarding profits of the industry}

A company may be restrained from external financing due to the uncertainty regarding profits of the industry. For precaution, the company will increase its proportion of cash holdings. Thus the second hypothesis is hereby presented:

H2a: the profit fluctuation of the industry is positively with the proportion of cash holding.

\subsubsection{Uniqueness of products}

The products of a specific industry have their own uniqueness. For example, there are significant differences between an AI product and the other ones. In general, the more particular the product is, the higher requirements regarding raw materials and technologies will be involved. More costs are required for raw material suppliers and manufacturers of products which have fewer rivals in the market. Based on this, the hypothesis is hereby presented:

H2b: The uniqueness of products of a listed company is positively related to its proportion of cash holding

\subsubsection{The degree of competition}

Conclusions made by existing studies regarding the influence by the degree of competition on the proportion of cash holdings are various. Like most literatures, this article holds that the more intense the competition, the more proportion of cash holding will be required, as the company needs 
more cash to cope with risks. As for companies listed on Chinese exchanges, the hypothesis is presented as follows:

H2c: The degree of product market competition for a listed company is positively related to the proportion of cash holdings.

\subsubsection{Asset structure of the industry}

This article holds that the liquidity and ability of a company to mortgage its tangible assets is closely related to the company's decision making on cashing holdings. Assets with more specificity are less. Thus they are unlikely to affect the liquidity of tangible assets. Based on this, the hypothesis is presented as follows:

H2d: the industry-related asset structure of a listed company (the proportion of tangible assets) is negatively related to the proportion of cash holdings.

\section{Definitions of Variables and Establishment of Models.}

\subsection{Establishment of theoretical models}

\subsubsection{Method for studying the inter-industry difference in cash holdings}

In order to verify H1, a descriptive statistical analysis was conducted on all of the data samples, and Kruskal-Wallis $\mathrm{H}$ method, one of non-parametric test methods, was used to verify whether cash holdings vary greatly between industries.

\subsubsection{Establishment of models for verifying the influence by the industry characteristics on cash holdings}

H2 was divided into four sub-hypotheses (H2a-H2d), which were used to study the influence by the four industry characteristics (the uncertainty regarding profits of the industry, uniqueness of specific products, the degree of product market competition, and the asset structure of industry) on cash holdings of listed companies. The generalized least squares method was used to establish the models for evaluation. The model (1) was as follows:

$$
\begin{aligned}
C H_{i j t}= & \beta_{1} T A N_{j t}+\beta_{2} U N I_{j t}+\beta_{3} H H I_{j t}+\beta_{4} V O P E_{j t}+\beta_{5} V R O E_{j t}+\beta_{6} V C F L_{j t}+\beta_{7} L E V_{j t}+ \\
& \beta_{8} T O B_{j t}+\beta_{9} I N V_{j t}+\beta_{10} T S H_{j t}+\alpha_{i}+v_{\mathrm{t}}+\varepsilon_{i j t}
\end{aligned}
$$

\subsection{Source and selection of data}

The data used in this article were obtained from wind database. The precondition for studying the inter-industry difference in the proportion of share holdings of listed companies is to clearly categorize the industries. So the industries were divided into categories according to the standards for the industry categorization of wind database.

The samples were selected between 2012 and 2016. And the companies listed on Shanghai and Shenzhen A-share exchanges before December 31, 2011 were selected as the study samples which were then screened by the following principles: (1) companies sustaining losses, namely ST and PT companies in negative equity should be ruled out first; (2) companies with incomplete data should be eliminated; (3) financial companies should not be taken into account. 


\section{Analysis on Empirical Results}

\subsection{Descriptive statistical results}

Table 1: Descriptive statistical results of cash holdings of listed companies (by industry, unit: \%)

\begin{tabular}{|c|c|c|c|c|c|c|c|c|c|c|}
\hline \multirow{2}{*}{$\begin{array}{l}\text { Industr } \\
\text { y }\end{array}$} & \multicolumn{2}{|c|}{2012} & \multicolumn{2}{c|}{2013} & \multicolumn{2}{c|}{2014} & \multicolumn{2}{c|}{2015} & \multicolumn{2}{c|}{2016} \\
\cline { 2 - 11 } & Mean & Sd & mean & sd & mean & sd & mean & sd & mean & sd \\
\hline A & 10.88 & 1.69 & 17.18 & 1.82 & 13.35 & 1.62 & 13.41 & 1.43 & 14.43 & 1.43 \\
\hline B & 15.02 & 1.72 & 15.76 & 1.54 & 11.19 & 0.85 & 11.27 & 0.87 & 10.65 & 0.67 \\
\hline C & 22.52 & 1.93 & 17.43 & 2.61 & 12.28 & 0.69 & 14.51 & 0.89 & 17.34 & 1.15 \\
\hline D & 25.94 & 0.85 & 17.25 & 1.49 & 14.99 & 1.11 & 16.51 & 1.16 & 17.63 & 1.34 \\
\hline E & 13.84 & 0.67 & 17.94 & 1.38 & 13.44 & 1.25 & 13.28 & 0.71 & 13.73 & 1.22 \\
\hline F & 14.94 & 1.12 & 19.2 & 1.77 & 21.29 & 1.39 & 15.35 & 0.99 & 20.68 & 1.51 \\
\hline G & 24.79 & 0.19 & 17.07 & 1.49 & 14.37 & 1.12 & 21.51 & 1.69 & 15.26 & 9.34 \\
\hline H & 27.98 & 2.53 & 16.27 & 1.38 & 20.01 & 2.32 & 20.36 & 2.09 & 20.29 & 1.71 \\
\hline I & 25.32 & 1.66 & 21.56 & 2.92 & 14.99 & 1.63 & 16.11 & 1.64 & 14.87 & 1.56 \\
\hline J & 45.02 & 1.98 & 20.63 & 1.96 & 23.47 & 2.95 & 25.25 & 2.32 & 26.25 & 2.52 \\
\hline K & 40.08 & 5.39 & 23.5 & 2.58 & 30.22 & 3.71 & 27.66 & 3.04 & 26.88 & 2.96 \\
\hline L & 26.73 & 3.49 & 19.61 & 2.08 & 17.45 & 1.6 & 17.7 & 1.52 & 17.98 & 1.52 \\
\hline M & 19.41 & 2.21 & 17.22 & 1.97 & 21.95 & 3.27 & 24.68 & 3.64 & 22.39 & 3.61 \\
\hline Total & 24.03 & 1.96 & 18.51 & 1.92 & 17.61 & 1.81 & 18.28 & 1.69 & 18.34 & 2.35 \\
\hline
\end{tabular}

\subsection{Verification of the difference in cash holdings between industries}

In order to further verify the statistical significance of the aforementioned difference, Kruskal Wallish test was applied on the difference in cash holdings between industries. The test results are shown in Table 2.

Table 2. Kruskal Wallish test results of cash holdings between different industries

\begin{tabular}{|c|c|c|c|c|c|}
\hline Year & 2012 & 2013 & 2014 & 2015 & 2016 \\
\hline Chi-square test value & 38.99 & 37.62 & 34.52 & 37.74 & 37.88 \\
\hline Degree of freedom & 12 & 12 & 12 & 12 & 12 \\
\hline P-value & $0.000^{* * *}$ & $0.000^{* * *}$ & $0.000^{* * *}$ & $0.01^{* * *}$ & $0.000^{* * *}$ \\
\hline
\end{tabular}

From the results we can see that $\mathrm{P}<0.01$, which indicates a significant confidence level. This means that there is a very significant difference in the proportion of cash holdings between different industries. What is more, statistical results of the five years are almost the same, which shows that the difference is fairly stable.

\subsection{Verification of the factors affecting the difference in cash holdings between industries}

The evaluation results of Model (1) are as follows. The research results of this article shows that the three indexes reflecting the change of profit rate, namely main business profit rate (VOPE), net asset return rate (VROE) and the ratio of net operating cash flow to total assets (VCFL), are positively related to the proportion of cash holdings, which supports H2. It is obvious that the more uncertainty that a company faces, the greater possibility that the company will encounter restrictions on financing. Thus the company must hold more cash for precautions, which meets the balance theory.

The results of the model show that index HHI of product market competition is significantly and 
positively related to the proportion of cash holdings. Because the degree of industry concentration (HHI) is negatively related to the degree of industry competition, we can see that the more intense the product market competition, the smaller the proportion of share holdings, which supports H2c.

The industry asset structure is significantly and negatively related to the proportion of cash holdings, and this negative relationship in multiple cases is very significant and stable, which proves H2d.

In conclusion, the industry characteristics of listed companies, such as the uncertainty regarding profits of the industry, uniqueness of specific products, the degree of product market competition, and the asset structure of industry, to a great extent affect the difference in cash holdings between industries, which meets $\mathrm{H} 2$.

Table 3. Results regarding the factors affecting the difference in cash holdings between industries

\begin{tabular}{|c|c|c|c|c|c|c|c|}
\hline $\begin{array}{l}\overparen{\Xi} \\
\frac{\mathbb{E}}{8} \\
\frac{0}{2}\end{array}$ & 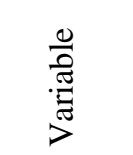 & (1) & (2) & (3) & (4) & (5) & (6) \\
\hline \multirow{12}{*}{ 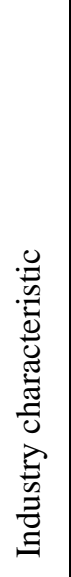 } & \multirow{2}{*}{ TAN } & $-0.227 * * *$ & $-0.221 * * *$ & $-0.192 * * *$ & $-0.209 * * *$ & $-0.223 * * *$ & $-0.219 * * *$ \\
\hline & & $(-5.95)$ & $(-6.01)$ & $(-4.13)$ & $(-5.03)$ & $(-4.91)$ & $(-5.54)$ \\
\hline & \multirow{2}{*}{ UNI } & & $0.124 * * *$ & $0.135^{* * *}$ & $0.176^{* * *}$ & $0.103^{* * *}$ & $0.909 * * *$ \\
\hline & & & $(4.43)$ & $(5.01)$ & $(4.70)$ & $(4.23)$ & $(4.24)$ \\
\hline & \multirow{2}{*}{ HHI } & & & $0.12 * * *$ & $0.141 * * *$ & $0.137 * * *$ & $0.122 * * *$ \\
\hline & & & & $(3.12)$ & $(2.93)$ & $(2.06)$ & $(3.14)$ \\
\hline & \multirow{2}{*}{ VOPE } & & & & $0.09 * * *$ & & \\
\hline & & & & & (3.14) & & \\
\hline & \multirow{2}{*}{ VROE } & & & & & $0.12^{* * *}$ & \\
\hline & & & & & & $(2.14)$ & \\
\hline & \multirow{2}{*}{ VCFL } & & & & & & $0.17^{* * *}$ \\
\hline & & & & & & & $\begin{array}{l}(3.84) \\
\end{array}$ \\
\hline \multirow{8}{*}{ 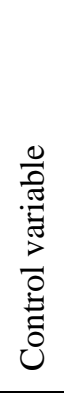 } & \multirow{2}{*}{ LEV } & $-0.185 * * *$ & $-0.127 * *$ & $-0.162 * * *$ & $-0.143 * *$ & $-0.154 * * *$ & $-0.148 * *$ \\
\hline & & $(-5.78)$ & $(-5.51)$ & $(-5.57)$ & $(-5.79)$ & $(-5.35)$ & $(-5.26)$ \\
\hline & \multirow{2}{*}{ TOB } & $0.021 * *$ & $0.016^{*}$ & $0.010^{*}$ & $0.018^{*}$ & $0.011^{*}$ & $0.016^{*}$ \\
\hline & & $(2.01)$ & $(1.71)$ & $(1.69)$ & $(2.21)$ & $(1.79)$ & $(2.31)$ \\
\hline & \multirow{2}{*}{ INV } & $-0.055 *$ & $-0.061^{* *}$ & $-0.061 * *$ & $-0.052^{*}$ & $-0.060 * *$ & $-0.062 *$ \\
\hline & & $(-1.87)$ & $(-1.97)$ & $(-1.99)$ & $(1.75)$ & $(-1.80)$ & $(1.85)$ \\
\hline & \multirow{2}{*}{ TSH } & 0.036 & 0.035 & 0.035 & 0.034 & 0.030 & 0.034 \\
\hline & & $(0.92)$ & $(1.12)$ & $(1.43)$ & $(1.32)$ & $(1.44)$ & $(1.34)$ \\
\hline \multirow{2}{*}{\multicolumn{2}{|c|}{ Constant term }} & $0.368 * * *$ & $0.381 * * *$ & $0.372 * * *$ & $0.377 * * *$ & $0.374 * * *$ & $0.374 * * *$ \\
\hline & & $(5.51)$ & $(5.46)$ & $(5.34)$ & $(6.12)$ & $(5.24)$ & $(6.22)$ \\
\hline \multicolumn{2}{|c|}{$\begin{array}{c}\text { Adjusted } \\
\text { R-squared }\end{array}$} & 0.211 & 0.231 & 0.245 & 0.257 & 0.301 & 0.293 \\
\hline
\end{tabular}

\section{Conclusion}

This article mainly studied the research on the industry characteristics of cash holdings of companies listed on Chinese exchanges. First of all, we discovered there is a significant difference in the proportion of cash holdings between industries. Then upon further study and verification, we found that the difference is closely related to and determined by the industry characteristics (long-term factors) which are the uncertainty regarding profits of the industry, uniqueness of 
specific products, the degree of product market competition, and the asset structure of industry. Therefore, it can be seen that the cash holdings of companies listed on Chinese exchanges are subject to the joint effects of multiple factors, which means it requires taking into account both internal and external factors of corporations in the analysis, especially the influence by industry characteristics on cash holdings (one of the external factors). In addition, the average proportion of cash holdings of an industry may serve as the reference for individual companies of the same industry to determine their optimal proportion of cash holdings. Holding insufficient or excessive cash to some extent will cause native results to a company's business operation and management. The findings of this article may provide an empirical support for a listed company to make decisions on cash holdings.

\section{References}

[1] Opler T, Pinkowitz L, Stulz R, et al. The determinants and implications of corporate cash holdings [J].Journal of Financial Economies, 1999, 52(1):3-46.

[2] Yang Xingquan and Wu Haomin. Industry Characteristics, Product Market Competition and Companies' Cash Holdings - an empirical evidence from companies listed in China [J]. Economic Review, 2009(01):69-76.

[3] Lian Yujun, Peng Fangping and Shuzhi. Financing Constraint and Liquidity Management Behavior. Journal of Financial Research, 2010, (10): 158 -171. 